\title{
Intersectionality and Invisible Victims: Reflections on Data Challenges and Vicarious Trauma in Femicide, Family and Intimate Partner Homicide Research
}

\author{
Patricia Cullen $^{1,2,3}$ (10 $\cdot$ Myrna Dawson ${ }^{4} \cdot$ Jenna Price $^{5} \cdot$ James Rowlands $^{6}$ \\ Accepted: 20 December 2020 / Published online: 3 February 2021 \\ (C) The Author(s), under exclusive licence to Springer Science+Business Media, LLC part of Springer Nature 2021
}

\begin{abstract}
Rigorous, comprehensive and timely research are the cornerstone of social and transformative change. For researchers responding to femicide, family and intimate partner homicide, there are substantial challenges around accessing robust data that is complete and fully representative of the experiences and social identities of those affected. This raises questions of how certain social identities are privileged and how the lens of intersectionality may be constrained or enabled through research. Further, there is limited insight into the emotional labour and safety for researchers, and how they experience and mitigate vicarious trauma. We examine these issues through a shared critical reflection and conclude with key recommendations to address the challenges and issues identified. Four researchers examining and responding to femicide, family and intimate partner homicide in Australia, Canada and the United Kingdom shared and evaluated their critical reflection. We drew on our experiences and offer insights into processes, impacts and unintended consequences of fatality reviews and research initiatives. There are substantial limitations in accessibility and completeness of data, which has unintended consequences for the construction of social identities of those affected, including how multiple forms of exclusion and structural oppression are represented. Our experiences as researchers are complex and have driven us to implement strategies to mitigate vicarious trauma. We assert that these issues can be addressed by reconceptualizing the goals of data collection and fostering collaborative discussions among those involved in data collection and violence prevention to strengthen research, prevention efforts and safety for all involved.
\end{abstract}

Keywords Femicide $\cdot$ Intimate partner violence $\cdot$ Family violence $\cdot$ Domestic violence $\cdot$ Homicide $\cdot$ Intersectionality $\cdot$ Vicarious trauma $\cdot$ Critical reflection

Patricia Cullen

patricia.cullen@unsw.edu.au

1 School of Population Health, Samuels Building, UNSW, NSW 2052 Sydney, Australia

2 The George Institute for Global Health, UNSW, NSW 2042 Newtown, Australia

3 Ngarruwan Ngadju: First Peoples Health and Wellbeing Research Centre, University of Wollongong, NSW 2500 Wollongong, Australia

4 Department of Sociology \& Anthropology, College of Social and Applied Human Sciences, University of Guelph, Guelph, Ontario N1G 2W1, Canada

5 Crawford School, Australian National University, ACT 2600 Canberra, Australia

6 Department of Sociology, School of Law, Politics and Sociology, University of Sussex, Brighton BN1 9QE, UK
No one should have to fear victimization in their homes or their daily public life. In the first situation, we know that women bear the greatest burden as the primary victims of violence in the home, including homicide (UNODC 2018). In public life, while men bear the largest burden of violence - overwhelmingly at the hands of other men - women also have much to fear. This too is largely from men, including street harassment, workplace harassment, sexual violence, and in some cases homicide.

Regardless of location, the killing of women can often be described as femicide and there is ongoing research examining the definitional parameters of this phenomenon. Where these killings occur in the context of an intimate or familial relationship, they are commonly referred to as 'family or intimate partner homicide'; while women are disproportionally affected, this term also captures the killings of men in these contexts. These deaths mean that in some way we, as a society, have failed. Our failure may be directly linked to actions or 
inactions of professionals, agencies, or systems. On the other hand, it may be indirect, perhaps reflecting wider issues like lack of awareness or ongoing problematic attitudes towards women and intimate relationships or structural inequities.

In response to these deaths, various forms of 'counting' have emerged, including domestic violence fatality reviews and femicide watches or observatories (Dawson 2017; Price 2019; Walklate et al. 2020). ${ }^{1}$ Although there are considerable differences between these approaches, in different ways they offer an unflinching review of a homicide, an opportunity to honour those who have died, and to be clear about perpetrator accountability, as well as reflect on our own individual, community and social understandings and responses. The promise is that by better understanding these deaths, we can identify learning and, consequently, improve professional and systems responses, as well as take other broader actions to bring about social and transformative change, including community education and awareness (Bugeja et al. 2015). To deliver that promise, research initiatives must be based on data which fully captures the nuances, and contextualises the events leading to the death. Moreover, this raises questions around how such nuances and complexities can be (or are) captured in data that are largely administrative in purpose, and consequently how this can shape the representation of the social identities of those affected.

From an intersectional perspective, there is an urgent need to attend to both how and what types of data we examine to develop prevention models that are responsive to intersecting systems and structures of oppression and exclusion. Furthermore, the emotional labour involved for researchers appears to be seldom considered, both as a matter of research but also in practice (Price 2019; Williamson et al. 2020). Yet, it can have significant implications, potentially on both the process and 'product' of prevention research.

To address these concerns, we embarked upon a shared critical reflection, which draws on and synthesises our diverse experiences as researchers examining and responding to femicide and/or family and intimate partner homicide in Australia, Canada and the United Kingdom (UK). Our overarching aim is to individually and collectively reflect on how our work responds to the need to document the similarities of these killings while also capturing their diversity as well as the structural drivers of femicide, family and intimate partner homicide. We examine the limitations around data and the impacts on the construction of social identities of those affected, including how intersecting forms of exclusion and structural

\footnotetext{
1 These are the two broad types of initiatives that have emerged with respect to 'counting' and, while there are variations with each, the two types differ in their general scope. Domestic violence fatality reviews focus primarily on killings that occur within the context of intimate partner homicide (and often also family homicide), whereas femicide watches/observatories focus only on the killings of women and girls and work to also capture deaths that occur outside the context of intimate or familial relationships.
}

oppression are represented in data (or not) and how intersectionality is constrained or facilitated in the processes of research. We also reflect on our own experiences as researchers with respect to why we do this work and how we do it safely. We conclude with some key recommendations to address the challenges and issues identified.

\section{Method}

Shared critical reflection was used as the method of enquiry to explore our lived experiences as researchers examining and responding to femicide, family and intimate partner homicide in Canada, Australia and the UK. Shared critical reflection is appropriate for considering the impact of structural and social systems on research and practice as well as for challenging hegemonic assumptions and inequities (Brookfield 2009). Our approach was informed by reflective practice, which seeks to "integrate thought and action, theory and practice, the academy and the everyday world, but also in the spirit of a constructivist approach to the variety of ways in which we construct the reality of problematic situations" (Schön 1992, p.123).

We are a group of researchers with diverse experiences and interests, engaging within and outside of higher education institutions, and we also have relevant experiences outside this context (Table 1). We are reflecting on the broad scope of our research, which ranges from femicide to a specific focus on family and intimate partner homicide. Where we use the term 'family and intimate partner homicide', we do so to indicate fatal violence within the context of intimate, familial and kinship relationships and circumstances - regardless of a range of different social identities, including for example, age, race/ethnicity, sex and/or gender and gender identity or expression, ${ }^{2}$ or sexual orientation. This recognises that hegemonic white, ableist, heteronormative, and sex and/or gender binary constructs very often determine how homicides are counted and understood.

Undertaken across three phases, the reflection was aligned with iterative thematic inquiry and analysis (Morgan and Nica 2020; Srivastava and Hopwood 2009). In the first phase, a problem definition was conceptualised during an initial collaborative discussion, and, in response, a guided reflection protocol was co-developed by all authors, which consisted of five over-arching points of reflection: 1) Context of the data $\mathrm{I} /$ we work with; 2) Who is represented or not in this data; 3 ) Representation of intersectionality in data and research; 4) Emotional labour and safety as researchers; 5) The change(s) $\mathrm{I} /$ we want to see.

\footnotetext{
${ }^{2}$ We recognise there are different views as to these categories, how they are understood and how they relate to each other. Our shared perspective is that the salient point is that how these are recorded is relevant.
} 
Table 1 Researcher descriptions detailing professional roles and experience
Dr Jenna Price Visiting Fellow, Australian National University; Columnist, Sydney Morning Herald and Canberra Times; Administrator, Counting Dead Women Australia

I was a university student in 1979 when I wrote my first story about family violence, the campaign to free Violet and Bruce Roberts, in the campus student publication. Violet and Bruce were convicted of the murder of Eric, husband and father, who had abused the family for years. The story of the unrelenting violence wasn't told in the trial. This seemed utterly unjust to me. The case of Violet and Bruce eventually made it possible for victims to reveal the effects of domestic violence but there was more work to do. For decades after, I wrote as many stories as editors would publish about domestic and family violence for mainstream news sites in Australia. In 2014, with other Australian feminist activists, the Counting Dead Women Australia project began, to record every single act of fatal violence against women (Cullen et al. 2019). At that time, I began a late onset PhD, where I explored feminist digital activism in Australia and its account of fatal violence against women using Counting Dead Women as a case study (Price 2019). It's a tortured trip from student activist to academic activist and practitioner of advocacy journalism.

Mr James Rowlands Doctoral Researcher, University of Sussex; Chair, Domestic Homicide Review

My practice and research interest is DHRs, the model of fatality review in England and Wales. As a practitioner, I have worked in the domestic violence sector for over 15 years and since 2016 have led DHRs. I am also completing a PhD, in which I am investigating the discursive practices of DHRs, in particular how victims are discursively constituted and what this makes possible in terms of knowledge production. The purposes of DHRs are learning, acting on and applying lessons learnt from domestic homicide; preventing domestic violence by improving service responses by intervening earlier; better understanding domestic violence and abuse; and highlighting good practice. DHRs are conducted into deaths linked to a former or current intimate partner, family member(s) or a member of the same household and are commissioned by the local area in which they occurred. They are led by an independent chair who works with a multi-agency panel. As a form of fatality review, DHRs have several particular features, including being a stand-alone review of each homicide that meets the criteria; an early commencement point, often running alongside the criminal justice process albeit with some safeguards; the central involvement of family; and commonly the publication of an (anonymised) report.

Professor Myrna Dawson Professor of Sociology, University of Guelph; Director, Centre for the Study of Social and Legal Responses to Violence; Director, Canadian Femicide Observatory for Justice and Accountability; Co-Director, Canadian Domestic Homicide Prevention Initiative

For the past 25 years, I have conducted research on violence with an emphasis on violence against women and children and specifically femicide. I have conducted comprehensive primary data collection using a variety of official sources (e.g. coroner/medical examiner data, police and Crown Attorney files) and publicly accessible sources (e.g. court documents, media stories). The main outcomes are two large-scale homicide databases. The first database began as a provincial-level study, documenting women killed in Ontario which was then expanded to all homicide victims in that one province. It is now being rolled out nationally in the Canadian Geography of Justice Initiative, documenting all homicides in Canada, and supporting the work of the Canadian Femicide Observatory for Justice \& Accountability (see www.femicideincanada.ca). The second database focuses on domestic violence-related homicides in Canada, representing one component of the Canadian Domestic Homicide Prevention Initiative with Vulnerable Populations, a national research initiative that aims to enhance risk assessment, risk management and safety planning for those experiencing domestic violence, specifically among four populations: Indigenous, immigrant/refugee, rural/remote/northern, and children killed in the context of domestic violence (see www.cdhpi.ca). Beyond these primary data collection activities, I have conducted secondary data analyses using the Statistics Canada Homicide Survey and the Uniform Crime Reports. I am also a long-time member of Ontario's Domestic Violence Death Review Committee and have used these data as well.

Dr Patricia Cullen Research Fellow, University of New South Wales; Honorary Fellow, The George Institute for Global Health \& Ngarruwan Ngadju, University of Wollongong

My perspective is informed by my own family and community experiences and as a public health researcher of intimate partner and family violence. I am leading a review of family and intimate partner homicide from the National Coronial Information System to understand the trajectories of violent deaths and opportunities for health system intervention. This expands my previous review of femicide that stemmed from collaborating with researchers from Counting Dead Women Australia, which was my first experience of homicide research in 2016. Through my research, I intend to bring a better understanding to the social and structural determinants of violence, as well as strengthening responses to address equity and prevent re-traumatisation.
In the second phase, three authors representing each of the three countries responded to the reflection protocol in writing and shared their responses with author PC to initiate the synthesis framework/process. PC undertook initial charting of data according to the five predetermined points of reflection and shared this with the other authors, so that they could reflect on each other's responses and consider how their experiences were similar and divergent.
In the final phase, through further collaborative discussion, we undertook inductive and deductive thematic synthesis. This involved considering the collective meanings of our reflections, as well as questioning how this was influenced by the lens through which we interpreted the points of reflection and our experiences. While this process was guided by the pre-determined reflection points, we continually refined these and formed new themes. Ultimately through iterations of 
examining our data in the context of our objectives, the data amalgamated into six over-arching themes that reflected where our shared experiences illuminated broader issues of importance. Through the peer-review process, we received valuable and constructive critiques, which provided impetus for further collaborative reflection and discussion. Through this discussion, we delved further into the ambiguities and uncertainties that are inherent in the data, as well as reignited our analysis of how intersectionality is operationalised in practical terms.

\section{Results}

First, we examine four themes that formed in response to our reflections on data: access to data; completeness of data; intersectionality; and invisible victims. Second, when we consider the impact of doing this work on researchers, two main themes formed around mitigating vicarious trauma and why, despite the challenges, we continue to do this work.

\section{Access to Data}

"For fatal violence against women to be considered as a national problem, it requires a change of thinking which, I argue, includes being able to recognise the extent of the challenge in a timely fashion" (Jenna). Femicide observatories have emerged in response to this challenge, to represent a death toll and focus the attention of the public onto the "terrifying regularity" of femicide. As such they present a picture, a frame, which, as stated by Ryan and Gamson (2006, p.13), organises thoughts, highlights "certain events and facts as important". The frame helps us build "a strategic dialogue intended to shape a particular group into a coherent movement". But none of that can happen if the necessary information is not available in a timely fashion. For femicide observatories, there is dependence on publicly accessible data, and the way that data are funnelled, most commonly through agency reports (e.g. media, police, coroner), impacts how readily it is accessible, how timely (or delayed) this access can be, and what data are available. For example, Counting Dead Women Australia has no official access to information about acts of fatal violence against women - but it has a range of women with expertise in searching relentlessly:

We look at police media feeds, news reports and coroner's reports, but we also receive tipoffs from the general public and, heartbreakingly, sometimes from family members who want their mothers, sisters, daughters included in our count. None of this is instant and it is by no means complete. (Jenna)
Access is also an issue in fatality review, although as a state mandated process, these tend to have formal reporting mechanisms, and can be analysed as a data source. Yet, James notes that in the UK, where DHRs should usually be published, there are often significant delays in doing so and some are not published at all (Benbow et al. 2018; Stanley et al. 2019). The lack of a national repository means the capacity to routinely produce aggregate data and learning is limited (Sharp-Jeffs and Kelly 2016).

\section{Completeness of Data}

The researchers agree there are common limitations across data sources in the relevant jurisdictions. There is shared frustration at both the rigour and timeliness of data collection but also at the extent to which individual, relationship and contextual variables are represented: "At the beginning, these women are bodies. By the end, they might have names and ages but to understand violence against women, we must know more. Location, employment, place of birth, ethnicity, religion, socioeconomic data" (Jenna). As an example, the Counting Dead Women Australia femicide census aims to count each death, however, this is constrained by the completeness of publicly available data.

In contrast, fatality reviews have access to a wide variety of information drawn from the criminal justice process, including the police or courts, and unlike the femicide census and observatories, routinely access other information from service providers, family and friends (Walklate et al. 2020). Thus, in theory, fatality reviews bring together rich sources of data to better understand the circumstances of homicides. However, there can be limitations. For example, there is considerable variation in both the style and quality of DHRs (Dawson 2017; Stanley et al. 2019), and some voices in reviews may be favoured over others (Robinson et al. 2018). Consequently, such reviews have been described as a 'partial account' of a homicide (Stanley et al. 2019). Furthermore, as documents, they are not necessarily produced with research in mind, making data extraction difficult, particularly when attempting to understand the context of a homicide and relationship dynamics (Chantler et al. 2020).

For example, one of the of most consistent and welldocumented correlates of intimate partner homicide is previous intimate partner violence; however, it is difficult to consistently capture this information in records kept by criminal justice organizations and often not even captured in a meaningful way by national statistical agencies [for fuller discussion see Dawson et al. 2019]. As Myrna notes: "The situation is exacerbated in the Canadian context because there is currently no specific domestic violence-related offence in our criminal code".

Moreover, given the concern around firearms-related homicide, particularly in rural regions, we have little to no 
information about firearms used to kill such as whether they were handguns or long guns, if they were licensed, or had been previously seized from the home, and so on (Zeoli et al. 2020). Understanding access to firearms as well as relationship dynamics and life situations are key to prevention, but we seldom get this information from official data sources and they may often not be collected, at least consistently, by national statistical agencies or fatality reviews.

It is only with complete data that we can begin to understand the structural aspects of homicide: "Given this situation, collecting data on structural determinants - poverty, colonization, discrimination, attitudes about gender norms - appears far out of reach, at least currently" (Myrna).

\section{Intersectionality}

Our reflections are aligned with the original intention of intersectionality, which means recognising that women of colour experience multiple competing burdens of racism and sexism (Crenshaw 1991). In the instance of violence, the physical assault is "merely the most immediate manifestation of the subordination they experience", writes Crenshaw (1991, p.1245). They are also burdened by "poverty, childcare responsibilities and the lack of job skills".

Currently, our administrative and national statistical systems are limited in their sophistication to capture multiple social identities, and the result is that intersecting identities are not well represented, particularly around sexual orientation, disability, mental health, racialised and Indigenous peoples. Collecting data around sex and/or gender has become a particularly challenging issue. On one hand, traditional data collection focusing on sex-based categories only does not capture the multiplicity or changeability of gender identity and expression (Ruberg and Ruelos 2020). Yet, at the same time, if official agencies or administrative data sources switch from collecting the category 'sex' to 'gender', without being able to disaggregate by sex at birth and so capture a transgender history, this makes it difficult to track male violence against females or violence against transgender persons. The latter of which was already difficult to collect given many instruments do not provide the space to capture gender identity or expression (Dawson and Carrigan 2020).

In practice, research can contribute to this problem through aggregation of cases based upon certain characteristics and the intersections are obscured. Consequently, certain social identities are privileged, as they are more readily captured in the data (e.g. age, country of birth, sex and/or gender, socioeconomic status of incident location) than others (e.g. disability, gender identity and expression, race/ethnicity, sexual orientation). For example, despite representing the initial and primary focus of intersectionality, race/ethnicity remains one of the most difficult social identities to capture, so systematically understanding how this identity combines with sex and/ or gender, ableism, and/or other identities to compound risk of violence, or impede safety, is almost impossible to do reliably: "The outcome of this has been the relative dearth of systematic research on groups who are most often marginalized and vulnerable to violence." (Myrna).

Where attempts are made to address the issue of representation, it can both mitigate and exacerbate this problem. Decisions are made about the focus of research, reflecting available data, the resources or other locally determined priorities. While this may render visible some identities, these decisions can also obscure others. To illustrate this, we noted two recent examples where there has been an attempt to attend to different identities in reporting aggregate findings, with different decisions being made in terms of prioritisation. In Canada, for example, recognizing the limitations of data around particular identities of marginalized and/or vulnerable groups, the Canadian Domestic Homicide Prevention Initiative is examining risk and safety for four groups: Indigenous, immigrant/refugee, rural/remote/northern, and children killed in the context of domestic violence. This includes the construction of a national domestic homicide database that seeks to capture more relevant detail although, given the focus of this paper, challenges are ongoing.

Working with a similar aim, a recent analysis of 84 DHRs in London, England focused on the experience of homicide victims from culturally and linguistically diverse backgrounds, Lesbian, Gay, Bisexual, Trans, Queer (LGBTQ+) communities, people with mental health issues and older people (Montique 2020). Moreover, researchers need to approach these categorisations with care, given they risk reifying specific categories and thus defeating the ambition of an intersectional perspective.

These issues are also pertinent in the expectation of fatality review and other research initiatives. For example, in the UK, the language around intersectionality is not used in the statutory guidance for DHRs, which instead includes a requirement to 'bear in mind equality and diversity issues at all times', with this framed as being about 'protected characteristics' (Home Office 2016). In their study of 141 DHRs, Chantler et al. (2020) found that ethnicity data were available for just over a half of victims and perpetrators but they cautioned that ethnicity may be more likely to be recorded where victims or perpetrators are not white.

The concept of intersectionality also draws attention to the combined effects of other social identities and so explores their compounding impact on risk and safety such as age, disability, rurality, and so on. The role of socioeconomic status - or poverty - and its impacts on risk of violence in combination with sex and/or gender and gender identity or

\footnotetext{
${ }^{3}$ The Equality Act 2010 makes it unlawful to discriminate against someone because of age, disability, gender reassignment, marriage and civil partnership, pregnancy and maternity, race, religion or belief, sex, or sexual orientation. These are called 'Protected Characteristics'.
} 
expression, race/ethnicity and other identities also remains largely unexamined in official data sources and those regularly accessed by violence prevention researchers.

In practice, the shortcomings in data drawn from official sources such as coroner/medical examiner, police and court reports, creates ambiguity and uncertainty in the practice of fatality review and other femicide and homicide research initiatives. Such ambiguity means that researchers must make decisions and assumptions about what is implied within the text of official reports. While it is often possible to tentatively conclude from the data examined that a victim was Indigenous or a perpetrator was an immigrant, it is not also, or even often, clearly stated or identified. The decision, then, becomes what threshold must be passed for a firm conclusion to be made from the data and for a case to be categorized as involving Indigenous or immigrant/refugee populations. Coding from official files inherently involves many such subjective decisions that impact the reliability of the data produced

When analysing published DHRs, researchers have to make a decision about what to code. For example, should social identities only be coded where they are explicitly stated, or it is possible to consider implicit content? Moreover, this data itself is dependent on the circumstances and manner of recording, ranging from a disclosure by a subject through to professional interpretation. Together these issues raise questions of both validity and reliability (James).

\section{Invisible Victims}

The outcome of the gaps in our data and knowledge, in short, is that those groups who are most marginalized and vulnerable to violence are often also the most invisible in terms of our efforts to develop prevention initiatives. When we consider who the invisible victims are, two groups emerge - those who are not counted and those who are undervalued. The deaths that are frequently not counted and are seemingly undervalued, particularly as femicides and intimate partner homicides, tend to be LGBTQ+, older victims, disabled victims as well as missing persons. In Australia and Canada, missing persons are disproportionately Indigenous and these deaths, as well as other racialized victims, are particularly undervalued in white hegemonic and colonial settler nations.

For decades in Australia and Canada, Indigenous women and girls have been killed at significantly higher rates than non-Indigenous women and girls and there is no better example of how important it is to document the structural determinants - perhaps more than individual determinants - given the ongoing legacy of colonisation and discrimination as drivers of their deaths: "In the Canadian context, a stark and disturbing example is the ongoing situation surrounding missing and murdered Indigenous women and girls." (Myrna). Likewise, in Australia, "Aboriginal women are invisible in our tolls. Sometimes we don't even hear of their deaths until months later, maybe years." (Jenna).

The role of structural drivers, including system barriers, is similarly experienced by other racialized women and girls globally who face increased marginalization and vulnerability (Ghafournia and Easteal 2018). This is further reinforced by their invisibility in all forms of official data, as it is "not even possible to accurately document their numbers let alone collect data on other social identities." (Myrna).

The counting of homicides itself can be problematic, dependent as it is on the discovery of a body, cause of death and then classification decision (Brookman and Maguire 2005). Fatality reviews may be triggered by the homicide, yet not all deaths are captured, and it is not clear how decisions are made to conduct reviews. In the UK, James notes that "the decision is made at a local level with some national oversight, but there is no requirement to publish information on notification and decisions, so the 'conversion' rate is unclear." In other scenarios, deaths may not be subject to review because of stereotypes (e.g. age, sexual orientation) that mean a death is not understood as occurring in a domestic abuse context (Rowlands 2020).

\section{Mitigating Vicarious Trauma and Generating Emotional Safety}

While robust data is essential, it is just as critical to have effective researchers - this requires that we consider our own emotional safety. In our experience, there can be a sense of closeness to the person who is the victim of the homicide (and perhaps others including children and even the perpetrator), which may be via the aural or written testimony of family or friends, or more indirectly via agency accounts: "Encountering the subject of homicide can provoke a range of emotional responses, including sadness and anger, as I grapple with the reality of a life lost, as well as frustration, when reflecting on missed opportunities or failed interventions." (James).

By contrast, working with data can be very technical and abstract at times, which can obscure the emotional impact. While there are cases that stay with you and linger in your thoughts, the process of self-reflection can be challenging and, in our experience, it can be hard to recognise if and how vicarious trauma may be manifesting.

I clearly remember one instance early in my new researcher life, still a graduate student, in which I returned home from a week spent reviewing parole board files on male homicide offenders. When I walked in the door of our home, my partner reached out to give me a hug and a kiss - a natural response on his part - to which I responded, "Don't touch me." (Myrna) 
It is not only the researching of homicide and violence. One way to educate and increase awareness is by speaking with the media, something we are frequently called upon to do. This can be extensive with multiple contacts and often little time to regenerate before the next woman or child is killed and we are asked to provide our "expertise"4: "This means constant exposure to these stories when deaths occur and we're asked for real time responses - and solutions, as if we hold all the answers, but just have not told anyone yet." (Myrna).

Furthermore, the response to publishing our work and our media commentary takes a toll, particularly in the face of relentless abuse and trolling. Trolling is a gendered phenomenon, disproportionately directed at women, and as some of us have experienced, even includes campaigns to discredit our work. There is a massive increase in men's rights activism, which are mobilised whenever feminists publish on gendered violence. Their attention is unrelenting and exhausting: "I was subject to a torrent of abuse and threats, including one troll threatening to come to my house and burn me alive. I couldn't write about fatal violence for weeks because I was so distraught." (Jenna). In contrast, men working in this field are not subject to the same scrutiny: "As a man working on domestic homicide, I face challenges, particularly if I am to be a reflective practitioner who is aware of my own structural privilege, but trolling is rarely one of them" (James).

Given these challenges around vicarious trauma and the emotional labour of both the work and the response to the work, we have generated strategies for accessing support and enhancing our emotional safety. This involves accessing formal (e.g. clinical supervision) and informal mechanisms through debriefing with supportive colleagues and loved ones.

I have learnt to take my emotional safety seriously. I access clinical supervision; I draw on the support of my colleagues; and also, my family and friends where needed. Critically, I take the opportunity to speak directly with family and friends, as well as survivors of domestic violence and abuse. That anchors me. A reminder of lived realities is, for me, a reality check that is both challenging but also vitalising. (James).

Nonetheless, this work can have an enduring impact, as Jenna notes:

There have been periods where this work has really disturbed me...For some reason, I bounce back. I talk about it too much. I ring friends to debrief (poor friends). I try to protect my family, but my spouse is a wonderful listener. He also reminds me to get off social media when it's out of control. Occasionally, I will tell a perfect stranger about the

\footnotetext{
${ }^{4}$ I am often uncomfortable using this term, but it captures the overwhelming emphasis that the media and others place on researchers and academics for their expertise, not recognizing that there is a variety of expertise that could be tapped into, including those who work within anti-violence organizations and survivors, many of whom have become advocates themselves (Myrna)
}

correspondence I get - that's partly because I'm overflowing and can't cope anymore. It's like runoff.

Even if we are fortunate enough to not have experienced the extent and forms of violence and abuse (and many are not that fortunate) that we read or hear about in the voices of the survivors/victims that we speak with, we recognize that we are impacted every time by what we read or the experiences of those whose stories we wish to know about or to tell to further prevention efforts. These impacts can be cumulative and lasting, and it may be particularly insidious when increasing education and awareness is a key component of our work: "You cannot discuss these cases over and over, including details of what happened and those involved, without experiencing some type of vicarious trauma, especially as you continue to ask yourself, "What more can we do?" (Myrna).

\section{"I Do This Work Because..."}

There are some clear tensions in why we do this work. On the one hand, we are driven by a clear sense of purpose in redressing the injustices of fatal violence, however, there is tension in understanding the magnitude of change needed, which at times can feel overwhelming: "I do this work because I think there are actions we can take to make family violence less likely. I imagine a world where family violence doesn't exist but it's unlikely to be like that in my lifetime" (Jenna).

Alongside this, there is hope and ambition, which arises from the purpose, that is, by telling a victim's story it may be possible to memorialise them and make a difference by leading to improved understanding or systems change: "Yet that is also tempered by a sense of repetition as we find the same learning time and time again, provoking despondency and the question, what does change?" (James).

Research is seen as an important driver of change and yet there is frustration in knowing we require robust data to support those changes: "I do this work because it is researchers who can collect data to help increase education and awareness, which is the core component of primary prevention, and increasingly recognized as key to moving forward if we are to achieve progress." (Myrna).

Underlying all of this, there are often pivotal personal and/or professional experience(s) that have compelled us to work in this space, and there is a sense of vicarious resilience that derives from the belief that the work matters and can make a difference.

I can still remember my first encounter with a death as a young social worker and domestic violence advocate. At the time I felt desperately sad, very alone and adrift: There was no way to be part of an accounting of what happened, and to learn if I or others could have done more or something different that may have prevented his death... I do this work because I believe it is possible to make a difference...domestic violence and abuse casts a long and 
devastating pall; despite welcome progress, it still seems sometimes to be understood as something that that is too big to end or will be always with us. I don't believe that is true. (James)

\section{Conclusions}

Despite different experiences collecting data and conducting research, there was considerable overlap in the issues identified that constrain the utility of data in prevention efforts, particularly around completeness of data and how this flattens social identities and renders many victims invisible. It is recognized that the completeness of the data - in other words, its reliability and validity for informing responses to, and the prevention of, femicide, family and intimate partner homicide - depends on the research questions we ask. However, through our collective reflections, we argue that current data sources are not sufficient for research with a focus on prevention, regardless of our research questions, particularly if we want to understand structural determinants of violence, but equally so for individual determinants of victimization and perpetration.

A key reason for these data gaps stems from the underlying rationale and goals of data collection by statistical and criminal justice agencies, which are not designed with research - or prevention - in mind (Dawson and Carrigan 2020). Rather, they are largely administrative in purpose and the types of data collected reflect administrative, not research or prevention goals. The exception may be fatality review initiatives whose primary focus is largely the prevention of future similar deaths. Therefore, data collected as part of the work of these initiatives may provide the most complete information on family or intimate partner homicide related deaths, and particularly those that end in the suicide of the accused - often not investigated as fully by police given that there are no subsequent criminal justice proceedings pending. However, there is significant variability across review teams, including how domestic abuse related homicides are defined and identified, the volume and type of materials reviewed, the voices heard, and the stakeholders or experts represented at the table (Dawson 2017). Thereby, data collected vary significantly, impacting what can be systematically used to inform intervention and prevention.

One key outcome of the difficulties of collecting even basic information on homicide is that our ability to understand risk and improve safety, particularly for marginalized and vulnerable populations, is impacted. In other words, our ability to apply an intersectional lens to prevention is precluded because we cannot access the information required to examine combinations of social identities (e.g. disabilities, gender identity and expression, race/ethnicity, sexual minority status, socio-economic status) that may increase a person's risk of homicide both at the individual and structural levels. Consequently, differential group risk remains constant for many and, more worrisome, is exacerbated by our inability to understand the varying challenges and obstacles that particular groups face due to oppression, colonization, discrimination, sexism, racism, ableism, and so on.

This has the long-term and negative consequence of making some groups of victims (e.g. Indigenous or racialized, poor women living with disabilities) less visible than other groups of victims (e.g. white, urban, able-bodied professional women). This is particularly pertinent in the era of the COVID-19 pandemic. While the pandemic has in many cases exacerbated existing inequities, it has also illuminated such inequities and experiences of violence. On the one hand, this makes issues of interpersonal and structural violence more difficult for dominant society, and particularly governments, to ignore. Yet it also underscores the critical need to have access to robust and timely data that accurately represents who is most at risk and where preventative efforts are ineffective and may be reinforcing existing structural oppression and exclusion.

Given the above, a key recommendation would be that we reconceptualize the purposes or goals of official data collection from the primarily administrative focus to prioritize, or at the very least, include, the routine collection of data that can inform the development of effective prevention initiatives (Dawson and Carrigan 2020). If we were to succeed in doing so, however, we would then have to address the issue of accessibility. Currently, access to most official data sources are largely restricted to those working within the organizations or closely affiliated, which is most often justified by issues of privacy and confidentiality. Privacy and confidentiality must be protected; however, this means that researchers who may be able to use these data for prevention rarely get to do so even though they are also concerned about privacy and confidentiality as a core part of their research ethics protocols and processes. The outcome is a wealth of data, albeit incomplete, that is largely sitting untouched and behind closed doors, often not contributing effectively to administrative goals either.

There is a growing recognition that much of our current data sources are often significantly flawed when it comes to identifying pathways for prevention, particularly for some groups who remain invisible. However, we continue to rely on them nonetheless. It becomes crucial, then, for the current and next generation of scholars to use our collective expertise and voices to call for systemic change when it comes to data collection. In part, it was this type of momentum and calls for change that gave rise to domestic violence death review committees. Such efforts need to continue to ensure that much needed data are available globally and not just in particular jurisdictions.

At the same time, we need to raise the voices of victims/ survivors through a greater emphasis on qualitative research that can help us better understand what that data has failed to underscore. Much data relies on the 'official' record, precluding the voices of those most profoundly impacted. The next generation of scholars can continue to push for the recognition 
of varying 'expertise' that can inform our prevention initiatives, including the expertise of victims/survivors.

When we considered our own goals and the personal impact of doing this work, there was a sense of vicarious resilience that comes with knowing why we do this work and the grounding that comes from working toward enacting systemic and social change. However, it also emerged that mitigating vicarious trauma was critical but also required us to firstly acknowledge that vicarious trauma does impact us and that we need to implement strategies that promote our emotional safety. It is essential that researchers of femicide and homicide are supported to generate practices that promote emotional safety in individuals and teams (Williamson et al. 2020); yet there needs to be a better understanding of how to do this effectively.

There is emerging insight into the impacts of vicarious trauma on researchers in the fields of suicide and trauma research, which predominately relates to researchers working in the field collecting primary data from people directly impacted by trauma (Chen et al. 2019; Smith et al. 2019). However, there is limited evidence and/or directives in this regard for homicide and femicide researchers. This perhaps reflects both reasons that compelled us to work in this space, associated stoicism, and a lack of appreciation for the potential traumatic impacts that comes from working with secondary data as opposed to collecting primary data.

However, many femicide and homicide researchers (ourselves included), are also frequently brought into contact with those who are directly impacted, whether it be first responders, family, and/or the broader community. This relates to the hidden toll and burden of responsibility that comes with advocacy and media communications, which is an essential component of our work. And finally, our own personal and family histories can be complex and at times fraught, and this can change over time and may interact with our work in seen and unseen ways (Fox and Wayland 2020). Researchers bring their own personal experiences and histories and are often personally impacted and invested in this work. Yet our own experiences can seem inconsequential in the context of homicide and femicide, and thus we may seek to minimise our own experiences. There is much to learn about how our own lived experience intersects with our experiences as researchers, as well as how this may signal vulnerability and the ways in which vicarious resilience and vicarious trauma can co-exist.

Much of what we do know about the impacts of vicarious trauma comes from research with frontline professionals who work directly with those experiencing trauma, which provides important learnings and recommendations that can be considered for femicide and homicide researchers (Hensel et al. 2015). Accordingly, we recommend that all researchers have appropriate training and awareness of vicarious trauma, as recognising the signs is critical to mitigating the impact (Sexual Violence Research Initiative 2015). Furthermore, strategies for frontline professionals and researchers can be applied to generate a culture of safety for femicide and homicide researchers, particularly around engaging formal supervision, debriefing with colleagues, managing work load and actions to promote self-care(Sexual Violence Research Initiative 2015).

At a systems level, research ethics committees, government agencies and academic institutions, which have a responsibility in regulating research safety, should mandate that researchers develop and implement protocols for homicide and femicide researcher safety, with appropriate monitoring and evaluation of uptake and implementation. This would need to be costed into project funding and approved by institutional and funding bodies. However, there are substantial barriers to realising this, which primarily relate to the gaps in our understanding of how this can be done effectively. Thus we need to invest in research to identify what works in preventing and responding to vicarious trauma (Molnar et al. 2017). Therefore, we strongly recommend that future research is directed toward identifying and implementing measures to better support the safety and wellbeing of femicide and homicide researchers.

Our experiences as researchers are complex, and we have found this process of shared critical reflection both cathartic and challenging. This process has built on and fortified our collective agenda to work collaboratively to prevent femicide and homicide. While we come from diverse personal and professional experiences, we recognise the limitations of our perspectives as white, privileged scholars from three Global North countries, which are white hegemonic nations fraught with historical and contemporary colonial manifestations. We anticipate that engaging in future critical reflections will involve a greater number of voices and perspectives. Thus, this reflective conversation among four researchers represents the start of a longer conversation and one which could be expanded across borders.

In conclusion, understanding how to improve the situations experienced by many - and perhaps most of us to some degree - requires information and the foundation of good information is good data. Therefore, it is critical that we reconceptualize the goals of data collection. It is also important to further engage in collaborative discussions between those involved in data collection and prevention initiatives so that there can be more effective use of the information being housed by organizations and institutions throughout the world. In this regard, it is encouraging that some agencies are beginning to understand how their data might be improved to capture key elements for prevention and are working with researchers and others to find ways to do so.

Acknowledgements We acknowledge the Counting Dead Women Australia researchers, and researchers at the Centre for the Study of Social and Legal Responses to Violence, University of Guelph.

Funding Patricia Cullen is funded by a National Health and Medical Research Council Early Career Fellowship; James Rowlands is funded by the Economic and Social Research Council, this work was supported by the Economic and Social Research Council [grant number ES/P00072X/1]. 


\section{Compliance with Ethical Standards}

Conflict of Interest The authors declare that they have no conflict of interest.

\section{References}

Benbow, S. M., Bhattacharyya, S., \& Kingston, P. (2018). Older adults and violence: An analysis of domestic homicide reviews in England involving adults over 60 years of age. Ageing and Society, 39, 1-25. https://doi.org/10.1017/S0144686X17001386.

Brookfield, S. (2009). The concept of critical reflection: Promises and contradictions. European Journal of Social Work, 12(3), 293-304. https://doi.org/10.1080/13691450902945215.

Brookman, F., \& Maguire, M. (2005). Reducing homicide: A review of the possibilities. Crime, Law and Social Change, 42(4), 325-403. https://doi.org/10.1007/s10611-005-1931-4.

Bugeja, L., Dawson, M., McIntyre, S.-J., \& Walsh, C. (2015). Domestic/ family violence death reviews: An international comparison. Trauma, Violence, \& Abuse, 16(2), 179-187. https://doi.org/10. $1177 / 1524838013517561$.

Chantler, K., Robbins, R., Baker, V., \& Stanley, N. (2020). Learning from domestic homicide reviews in. England and Wales., 28(2), 485-493. https://doi.org/10.1111/hsc. 12881.

Chen, J. I., Mastarone, G. L., \& Denneson, L. M. (2019). It's not easy impacts of suicide prevention research on study staff. Crisis, 40(3), 151-156. https://doi.org/10.1027/0227-5910/a000595.

Crenshaw, K. (1991). Mapping the margins: Intersectionality, identity politics, and violence against women of color. Stanford Law Review, 43(6), 1241-1299. https://doi.org/10.2307/1229039.

Cullen, P., Vaughan, G., Li, Z., Price, J., Yu, D., \& Sullivan, E. A. (2019). Counting dead women in Australia: An in-depth case review of femicide. Journal of Family Violence, 34(1). https://doi.org/10. 1007/s10896-018-9963-6.

Dawson, M. (2017). Domestic homicides and death reviews: An international perspective. London: Palgrave Macmillan.

Dawson, M., \& Carrigan, M. (2020). Identifying femicide locally and globally: Understanding the utility and accessibility of sex/genderrelated motives and indicators. Current Sociology.https://doi.org/10. 1177/0011392120946359.

Dawson, M., Sutton, D., Carrigan, M., Grand'Maison, V., Bader, D., Zecha, A., \& Boyd, C. (2019). \#CallItFemicide: Understanding Gender-based Killings of Women and Girls Guelph. ON:Centre for the Study of social and legal responses to violence.

Fox, M., \& Wayland, S. (2020). When you become the lived experience: The journey backwards from academia. Aotearoa New Zealand Social Work, 32(2). https://doi.org/10.11157/anzswjvol32iss2id739.

Ghafournia, N., \& Easteal, P. (2018). Are immigrant women visible in Australian domestic violence reports that potentially influence policy? Laws, 7(4).

Hensel, J. M., Ruiz, C., Finney, C., \& Dewa, C. S. (2015). Meta-analysis of risk factors for secondary traumatic stress in therapeutic work with trauma victims. Journal of Traumatic Stress, 28(2), 83-91. https://doi.org/10.1002/jts.21998.

Home Office. (2016). Multi-agency statutory guidance for the conduct of domestic homicide reviews. Retrieved from London: https://assets. publishing.service.gov.uk/government/uploads/system/uploads/ attachment data/file/575273/DHR-Statutory-Guidance-161206.pdf

Initiative, S. V. R. (2015). Guidelines for the prevention and management of vicarious trauma among researchers of sexual and intimate partner violence. South Africa: Retrieved from Pretoria.
Molnar, B., Sprang, G., Killian, K. D., Gottfried, R., Emery, V., \& Bride, B. E. (2017). Advancing science and practice for vicarious traumatization/secondary traumatic stress: A research agenda. Traumatology, 23, 129-142.

Montique, B. (2020). Domestic homicide review case analysis and review of local authorities DHR process. Retrieved from London: Standing Together Against Domestic Violence and London Metropolitan University https://www.standingtogether.org.uk/dhr.

Morgan, D. L., \& Nica, A. (2020). Iterative thematic inquiry: A new method for analyzing qualitative data. International Journal of Qualitative Methods, 19. https://doi.org/10.1177/ 1609406920955118.

Price, J. (2019). Destroying the joint: A case study of feminist digital activism in Australia and its account of fatal violence against women. Sydney: The University of Sydney Retrieved from https://ses.library.usyd.edu. $\mathrm{au} / \mathrm{bitstream} /$ handle $/ 2123 / 21156 /$ price $\mathrm{j}$ thesis.pdf;jsessionid= 223C9E3D1D77A39A9688C2BE63E3991C?sequence=2.

Robinson, A. L., Rees, A., \& Dehaghani, R. (2018). Making connections: A multi-disciplinary analysis of domestic homicide, mental health homicide and adult practice reviews. The Journal of Adult Protection, 21(1), 16-26. https://doi.org/10.1108/JAP-07-2018-0015.

Rowlands, J. (2020). Reviewing domestic homicide - International practice and perspectives. Retrieved from London: https://www.wcmt. org.uk/users/jamesrowlands2019

Ruberg, B., \& Ruelos, S. (2020). Data for queer lives: How LGBTQ gender and sexuality identities challenge norms of demographics. Big Data \& Society., 7, 205395172093328. https://doi.org/10.1177/ 2053951720933286.

Ryan, C., \& Gamson, W. A. (2006). The art of reframing political debates. Contexts, 5(1), 13-18.

Schön, D. A. (1992). The theory of inquiry. Dewey's legacy to education Curriculum Inquiry, 22(2), 119-139.

Sharp-Jeffs, N., \& Kelly, L. (2016). Domestic homicide review case analysis. Retrieved from London: Standing Together Against Domestic Violence and London Metropolitan University https:// www.standingtogether.org.uk/dhr.

Smith, A. M., Hamilton, A. B., Loeb, T., Pemberton, J., \& Wyatt, G. E. (2019). Reactions of novice interviewers conducting trauma research with marginalized communities: A Qualitative Analysis. Journal of Interpersonal Violence. https://doi.org/10.1177/ 0886260519889925.

Srivastava, P., \& Hopwood, N. (2009). A practical iterative framework for qualitative data analysis. International Journal of Qualitative Methods, 8(1), 76-84. https://doi.org/10.1177/ 160940690900800107.

Stanley, N., Chantler, K., \& Robbins, R. (2019). Children and domestic homicide. The British Journal of Social Work, 49(1), 59-76. https:// doi.org/10.1093/bjsw/bcy024.

United Nations Office on Drugs and Crime. (2018). Global study on homicide 2019. Retrieved from Vienna:

Walklate, S., Fitz-Gibbon, K., McCulloch, J., \& Maher, J. (2020). Towards a global femicide index: Counting the costs. New York: Routledge.

Williamson, E., Gregory, A., Abrahams, H., Aghtaie, N., Walker, S.-J., \& Hester, M. (2020). Secondary trauma: Emotional safety in sensitive research. Journal of Academic Ethics, 18(1), 55-70. https://doi.org/ 10.1007/s10805-019-09348-y.

Zeoli, A. M., Malinski, R., \& Brenner, H. (2020). The intersection of firearms and intimate partner homicide in 15 nations. Trauma Violence Abuse, 21(1), 45-56. https://doi.org/10.1177/ 1524838017738725 .

Publisher's Note Springer Nature remains neutral with regard to jurisdictional claims in published maps and institutional affiliations. 